Rev. Interd. em Cult. e Soc. (RICS), São Luís, v. 6, n. 1, p. 164- 172, jan./jun. 2020

ISSN eletrônico: 2447-6498

\title{
O Diário de Anne Frank: Literatura e Turismo Cultural entrelaçados nos Lugares de Memória ${ }^{1}$
}

\author{
Anne Frank's Diary: Literature and Cultural Tourism intermingled in \\ Memory's Places
}

\author{
AREMYS NASCIMENTO SANTOS \\ Mestre pelo Programa de Pós-Graduação em Cultura e Sociedade (UFMA) \\ symeras@yahoo.com.br
}

\author{
ABERTURA \\ Tenho vontade de escrever e uma \\ necessidade ainda maior de desabafar \\ tudo o que está preso em meu peito. \\ [...] \\ A não ser que você escreva, não saberá \\ como é maravilhoso; eu sempre \\ reclamava de não conseguir desenhar, \\ agora me sinto felicíssima por saber \\ escrever. E, se não tiver talento para \\ escrever livros ou artigos de jornal, \\ sempre posso escrever para mim mesma. \\ [...] quero continuar a viver, mesmo \\ depois da minha morte! \\ (O Diário de Anne Frank)
}

\section{RESUMO}

Os diários se constituem uma forma singular de expressão literária e, muitas vezes, histórica, pois registram acontecimentos que marcaram uma época. Dentre as escritas desse teor, pode-se destacar $O$ Diário de Anne Frank, onde são registrados o dia a dia dessa adolescente judia de treze anos que teve sua liberdade ameaçada com a ocupação nazista na Holanda, tendo que se confinar com sua família e alguns amigos nos fundos de um prédio, cujo pai era o dono, até serem descobertos em 1944. Analisa-se neste artigo a narrativa de Anne Frank com seu diário, sua relação de refugiada dentro da própria cidade em que escolheu viver, a sua escrita contundente e opiniões em relação aos seus familiares e moradores do Anexo. E ainda a relação da Literatura e do Turismo que abordam caminhos diferentes, mas que convergem em saberes e conhecimento que tal interdisciplinaridade proporciona. Para tanto tem-se como aporte teórico a Geografia Humanista Cultural a partir do expoente geógrafo Yi-Fu Tuan, os estudos relativos à memória em Maurice Halbwachs, bem como a reflexão de Margarita Barreto e Mário Petrocchi em relação ao turismo.

Palavras-chave: O Diário de Anne Frank. Escrita de si. Memória. Turismo Cultural.

\section{ABSTRACT}

The diaries are a unique form of literary expression, and often historical, because they record events that marked an epoch, among the writings of this content, it can be highlighted: Anne Frank's diary, in this diary are recorded the daily routine of this thirteen-year-old Jewish girl who had her freedom threatened by Nazi occupation in the Netherlands, having to confine herself with her family and friends in the back of a building, whose father owned it, until they were discovered in 1944. This article analyzes Anne Frank's narrative in her diary, her refugee condition within the city she chose to live in, her blunt writing,

\footnotetext{
${ }^{1}$ Artigo submetido para avaliação em 10/10/2019 e aprovado em 20/10/2019.
} 
Rev. Interd. em Cult. e Soc. (RICS), São Luís, v. 6, n. 1, p. 164- 172, jan./jun. 2020

ISSN eletrônico: 2447-6498

and opinions regarding her family and Annex residents. And also the relationship of literature and tourism that approach different paths but that converge to knowledge that such interdisciplinarity provides. For such, it has as theoretical contribution the Cultural Humanist Geography in the exponent of Yi-Fu-Tuan, the studies related to the memory of Maurice Halbwachs, as well as the reflection of Margarita Barreto and Mario Petrocchi in relation to tourism.

Keywords: Anne Frank's diary. Writing of the self. Memory. Cultural tourism.

\section{INTRODUÇÃO}

Annelies Marie Frank. Esse era o nome da adolescente judia que tinha uma vida normal até 1942. Com a chegada dos nazistas à Holanda, viu sua rotina mudar completamente, assim como os seus planos, seus sonhos, enfim sua vida inteira. Obrigada a se refugiar em um abrigo com a família, pai, mãe e irmã, além de mais quatros pessoas, de criança feliz e esperançosa, a uma adolescente preocupada com o futuro agora incerto, Anne Frank expõe em seu diário as atrocidades cometidas pelos alemães nazistas em sua chegada à Holanda. $\mathrm{Na}$ sua narrativa, encontra-se todo o sofrimento do povo judeu que sofreu o holocausto. O Diário de Anne Frank é tido como um dos livros mais importantes do século XX, tendo sido considerado Patrimônio da Humanidade pela UNESCO. A convivência com outras pessoas, a relação conturbada com a mãe, o descobrimento do amor, seus planos, sonhos, angústias e tristezas, além dos relatos terríveis das atrocidades cometidas pelos nazistas, fazem deste livro muito mais que um simples diário, mas um documento histórico de extrema importância para a humanidade.

\section{A ESCRITA DE SI}

O fato de escrever me levantou um pouco das "profundezas do desespero".

(Anne Frank)

Anne Frank possuía o sonho de ser escritora. No início, quando ganhou seu diário, registrava apenas acontecimentos do seu cotidiano, sua vida na escola, em família, sem muita profundidade, mas depois que ouviu um discurso no rádio, seu pensamento mudou completamente:

[...] certo dia de 1944, Gerrit Bolkesteian, membro do governo holandês no exílio, declarou em transmissão radiofônica que, depois da guerra, esperava recolher testemunhos oculares do sofrimento do povo holandês sob ocupação alemã e que estes pudessem ser postos à disposição do público. Referiu-se especificamente a cartas e diários. (FRANK, 2013, p. 7) 
Rev. Interd. em Cult. e Soc. (RICS), São Luís, v. 6, n. 1, p. 164- 172, jan./jun. 2020 ISSN eletrônico: 2447-6498

O diário de Anne Frank foi escrito entre 12 de junho de 1942 e $1^{\circ}$ de agosto de 1944 e foi graças a esse anúncio que Anne Frank teve a ideia de escrever um livro a partir do seu diário, fazendo várias modificações em termos de organização, melhoras no texto, alterações de passagens, tudo isto ao mesmo tempo em que escrevia em seu diário original.

Os diários fazem parte da vida de muitas pessoas, e nessas páginas escrevem-se os mais diversos acontecimentos, sobretudo os acontecimentos pessoais, de quem se gosta, de quem não se gosta, enfim, as histórias do cotidiano de cada um ou o que se achar importante para deixar registrado, o que merece ser imputado na História: "Escrever cada dia sob a garantia desse dia, é para lembrá-lo a si mesmo, é uma maneira cômoda de escapar ao silêncio[...] cada dia nos diz alguma coisa. Cada dia anotado é um dia preservado. (BLANCHOT, 2005, p. 273).

Desse modo escrever é como continuar a existir, ainda que no papel, talvez uma forma de se eternizar pelas palavras. Ou como ela mesma dizia: "o papel tem mais paciência do que as pessoas" (FRANK, 2013, p. 19). Talvez por isto Anne se sentisse muito à vontade em escrever no diário. Escrevia com desenvoltura e falava das características das pessoas de forma observadora, com uma percepção rara, incomum para alguém de sua idade.

A escrita de si traz uma gama de sentimentos que, ao serem expressos no papel, adquirem novos sentidos relevantes para a memória: “A memória é uma reconstrução psíquica e intelectual que acarreta de fato uma representação seletiva do passado que nunca é aquele do indivíduo somente, mas de um indivíduo inserido num contexto familiar, social, nacional". (HALBWACHS, 1998, p. 94). Isto nos remete ao episódio em que Anne Frank inicia os preparativos para sua ida ao esconderijo secreto:

\footnotetext{
Margot e eu começamos a pôr nossos pertences mais importantes numa pasta da escola. A primeira coisa que agarrei foi este diário e, depois, rolinhos de cabelos, lenços, livros da escola, um pente e algumas cartas antigas. Preocupada com a ideia de ir para um esconderijo, juntei as coisas mais malucas na pasta, mas não me arrependo. Para mim, as lembranças são mais importantes do que os vestidos. (FRANK, 2013, p. 33)
}

Diante desse contexto de fuga, de união familiar, tem-se a ideia de reter na memória o máximo possível de informações, juntamente com objetos que lhes são caros ou talvez pelo fato de uma possível destruição iminente. A relação de Anne Frank com o diário é tão profunda que ela carinhosamente o apelida de "Kitty" e o tinha como melhor amigo; aliás esse é um dos motivos que fez com que ela tivesse um diário. Em 
Rev. Interd. em Cult. e Soc. (RICS), São Luís, v. 6, n. 1, p. 164- 172, jan./jun. 2020 ISSN eletrônico: 2447-6498

sua concepção, não possuía verdadeiros "amigos" e Kitty seria o mais fiel de todos. No início do diário, ela diz: "espero poder contar tudo a você, como nunca pude contar a ninguém, e espero que você seja uma grande fonte de conforto e ajuda". (FRANK, 2013, p. 11). Percebe-se que a relação de Anne Frank com o diário é de uma amiga que a ajudou a suportar as angústias e a situação de isolamento em que vivia:

Até agora você tem sido um grande apoio para mim, como também tem sido Kitty, para quem tenho escrito com regularidade. Esse modo de manter um diário é bem melhor, e agora mal posso esperar os momentos de escrever em você. Ah, estou tão feliz por ter você comigo! (FRANK, 2013, p. 13)

A narrativa de suas esperanças faz com que sinta uma angústia dolorosa ao pensar no futuro que a aguardava.

\section{O ANEXO SECRETO E A GEOGRAFIA DO LUGAR: UMA PERCEPÇÃo HUMANISTA}

Eu moro em mim mesmo. Não faz mal que o quarto seja pequeno. É bom, assim tenho menos lugares para perder as minhas coisas.

(Mário Quintana)

Difícil imaginar a situação que Anne Frank, sua família e amigos tiveram que suportar durante dois anos e um mês. O Anexo Secreto, como foi batizado o esconderijo, era um prédio que, durante o dia, servia de escritório de trabalho e acima de qualquer suspeita, como descrito por Anne Frank:

[...] o grande armazém no andar térreo é usado como sala de trabalho e depósito, e é dividido em várias seções, como a sala de estoque e a sala do moinho, onde são moídos cravo, canela e um substituto de pimenta. Junto à porta do armazém há outra porta externa, uma entrada separada para o escritório. Logo depois há uma outra porta e atrás dela uma escada. [...] A porta á direita do patamar leva ao Anexo Secreto nos fundos da casa. Ninguém jamais suspeitaria da existência de tantos cômodos por trás daquela porta cinza e lisa. (FRANK, 2013, p. 37)

Assim era o esconderijo em que Anne Frank ficou confinada. Não eram de se estranhar os muitos sentimentos que esse lugar lhe trazia; o fato de não poder sair, de não abrir as janelas ou só quando estava escuro, falar alto e até tossir eram movimentos considerados perigosos, pois poderiam fazer com que fossem descobertos, o que trazia uma constante sensação de angústia. O lugar em que se vive de certa forma influencia os sentimentos de seus moradores, moldando assim seu modo de agir, de se comportar, 
Rev. Interd. em Cult. e Soc. (RICS), São Luís, v. 6, n. 1, p. 164- 172, jan./jun. 2020 ISSN eletrônico: 2447-6498

como atesta Tuan (2013, p.144): “A arquitetura continua a exercer um impacto direto sobre os sentidos e os sentimentos. O corpo responde como sempre tem feito, aos aspectos básicos do plano como interior e exterior, verticalidade e horizontalidade, massa, volume, espaciosidade, interior e luz".

Diante desses impactos causados pela vivência de estar-se num lugar isolado, aparecem sentimentos como o apinhamento e espaciosidade, termos intimamente relacionados à Geografia Humanista Cultural e que representam sentimentos ou sensações causadas pelo uso do espaço. Opostos, têm suas especificidades. "Espaciosidade está intimamente associada com a sensação de estar livre. Liberdade implica espaço, significa ter espaço suficientes em que atuar. (TUAN, 2013, p. 72). Já apinhamento traz a sensação contrária; o que para TUAN (2013) significa estar num lugar limitado ou sentir-se limitado com a falta de espaço na esfera social, onde haveria desejos frustrados, onde a liberdade seria algo difícil de ser alcançada.

No esconderijo, essa movimentação era praticamente impossível, pois, apesar de ser "espaçoso", o lugar não trazia espaciosidade, ou seja, não se tinha a sensação de liberdade: “[...] não importa o que façamos, temos muito medo que os vizinhos possam nos ver ou ouvir. Desde o primeiro dia começamos imediatamente a costurar cortinas". (FRANK, 2013, p. 41).

A experiência de ter que viver com essas práticas, em tese, obrigatórias para que Anne e os seus se sentissem mais seguros, ora costurando cortinas ou, como ela mesma chamava, "retalhos de pano", já que não se assemelhavam realmente às cortinas que costumavam usar para cobrir as janelas, ora falando baixo para não ser ouvida, Tuan (2013, p. 17) assim conceitua:

[...] um termo que abrange as diferentes maneiras por intermédio das quais uma pessoa conhece e constrói a realidade. Essas maneiras variam desde os sentidos mais diretos e passivos como o olfato, paladar e o tato, até a percepção visual e a maneira indireta de simbolização.

Tendo desse modo sua liberdade tolhida, não era de se estranhar que os sentimentos ou sensações que Anne tinha por este lugar fossem contraditórios. Às vezes, ela o sentia como um abrigo, um lugar seguro, onde podia escapar dos seus algozes; em outras, se sentia presa, impaciente e, eventualmente, infeliz. Nesse sentido, percebe-se uma sensação de apinhamento, o sentir-se acuado, sem plenitude, o que pode levar à solidão: “[...] estou rodeada por um vazio muito grande. Eu não costumava 
Rev. Interd. em Cult. e Soc. (RICS), São Luís, v. 6, n. 1, p. 164- 172, jan./jun. 2020 ISSN eletrônico: 2447-6498

pensar muito nele, já que tinha a mente cheia de meus amigos e de diversão. Agora penso sobre coisas infelizes ou sobre mim mesma". (FRANK, 2013, p. 88).

Outro sentimento marcante de Anne Frank em relação ao esconderijo era o de topofobia em relação ao lugar, que se opõe à topofilia, como se evidencia em vários trechos de sua narrativa: "[...] Mas gostaria de pelo menos uma vez me divertir de verdade, e de rir tanto a ponto de sentir dor, estamos trancados nesta casa como se fôssemos leprosos, especialmente durante o inverno, o Natal e os feriados de AnoNovo" (FRANK, 2013, p. 175). Ou ainda "sempre que vem alguém de fora, com o vento nas roupas e o frio nas bochechas, sinto vontade de enterrar a cabeça debaixo dos cobertores para não pensar: Quando será que poderemos respirar ar puro de novo?" (FRANK, 2013, p. 176).

Para Tuan (2012), topofilia seria a ligação afetiva entre o homem e o lugar em que ele vive, incluindo o meio ambiente material, podendo variar de intensidade, desde uma apreciação mais estética da beleza ao prazer tátil de sentir o ar, a terra, a água, tudo isto de uma maneira mais profunda. Já topofobia seria o sentimento de aversão ao lugar, ao meio em que se vive.

Uma outra questão que pode ser percebida durante a narrativa de Anne Frank é a que envolve Identidade. Para Hall (2011, p. 49), “[...] as identidades nacionais não são coisas com as quais nós nascemos, mas são formadas e transformadas no interior da representação. [...]”. De acordo com esse pensamento, podemos perceber que para Anne sua identidade estava sendo colocada em xeque, pois sendo uma alemã judia e sendo precisamente perseguida por alemães nazistas, algo que tempos atrás seria impensável para ela, seria natural sua aversão em relação a sua própria identidade, tal como ela mesma atesta: "Excelentes espécimes de humanidade, esses alemães e pensar que na verdade sou um deles! Não, isso não é verdade, Hitler retirou nossa nacionalidade há muito tempo. E além disso, não há maiores inimigos na terra do que alemães e judeus". (2013, p.71).

Ou ainda, em outra passagem mais reveladora do seu modo de pensar: "É necessário falar baixo o tempo todo. Somente devem ser faladas línguas de pessoas civilizadas, portanto, nada de alemão" (FRANK, 2013, p. 84). E pensar que todo sofrimento, limitações e conflitos eram causados por aqueles que se julgavam superiores, ainda assim, percebe-se, na escrita de Anne Frank, uma maturidade desproporcional para sua idade. 
Rev. Interd. em Cult. e Soc. (RICS), São Luís, v. 6, n. 1, p. 164- 172, jan./jun. 2020 ISSN eletrônico: $2447-6498$

Hoje, passados vários anos deste acontecimento que marcou a história da humanidade, a memória do lugar permanece e em muitos casos torna-se ponto de visitação turística, como o Anexo Secreto que se tornou uma casa-museu e mesmo os campos de concentração ou de trabalhos forçados como Bergen-Belsen, para onde Anne Frank e sua irmã Margot foram levadas.

\section{LITERATURA E TURISMO CULTURAL NOS LUGARES DE MEMÓRIA}

Não há melhor fragata que um livro para nos levar a terras distantes. (Emily Dickinson)

Escrever para Anne Frank era de suma importância, assim como a leitura de um bom livro, didático ou não, a ajudava a escapar um pouco da "prisão" em que se encontrava: "As pessoas comuns não sabem quanto os livros significam para alguém escondido. Nossas únicas diversões são ler, estudar e ouvir rádio". (FRANK, 2013, p. 127). Os livros estavam entre seus presentes de aniversário prediletos, sendo o de mitologia-greco-romana o que de mais gostava:

\footnotetext{
Vou comentar mais sobre os meus matadores de tempo (é assim que chamo meus cursos, porque tudo o que fazemos é tentar fazer com que os dias passem o mais rápido possível para estarmos mais perto do fim de nossa estada aqui). Adoro mitologia, sobretudo deuses gregos e romanos. Todo mundo acha que meu interesse é mania passageira, pois nunca ouviram falar de uma adolescente que goste de mitologia. Bom, então sou a primeira! (FRANK, 2013, p.113).
}

Os outros "matadores de tempo" do qual Anne fala são o curso de taquigrafia e o aprendizado da língua francesa, pelos quais demonstrava grande interesse, o que denotava uma busca por um certo equilíbrio através da leitura, numa tentativa de manter uma vida mais perto da normalidade possível. A Literatura, por sua própria natureza, permite os mais variados diálogos com outras disciplinas, a exemplo do Turismo. Muitas pessoas unem o útil ao agradável quando se valem de livros e viagens, o que pode remeter à prática turística do turismo cultural, em que são valorizados lugares que ficaram marcados na história e na memória.

O turismo cultural pode ser uma maneira de disseminar o modo de ser e de viver de um povo, proporcionando maior compartilhamento de informações, para que a memória do 
Rev. Interd. em Cult. e Soc. (RICS), São Luís, v. 6, n. 1, p. 164- 172, jan./jun. 2020 ISSN eletrônico: 2447-6498

lugar seja preservada e sua divulgação seja expandida, atraindo a comunidade local e turistas. Barreto (2007) acentua que turismo cultural é todo turismo no qual o principal atrativo não é a natureza, mas um aspecto da cultura humana que pode ser a história, o cotidiano, o artesanato, etc. Diante desse processo, surgem modalidades ou segmentos dentro do turismo cultural, dentre os quais podemos citar o Thanaturismo.

Chama-se de Thanaturismo a prática turística onde há visitas, intencional ou por outras razões, a locais que possam oferecer a representação da morte ou do sofrimento. Nesses lugares, aconteceram tragédias, desastres naturais ou causados pelo homem, ou mortes que marcaram as pessoas e que, de certa forma, continuam a causar impacto. (PETROCCHI, 2009).

Além da casa-museu Anne Frank, também podem ser visitados o campo de concentração ou de (trabalhos forçados) para onde Anne e sua irmã Margot foram levadas após o descobrimento do esconderijo, em Bergen-Belsen, na Alemanha. Há nesse lugar um memorial das duas irmãs, visto que seus corpos nunca foram encontrados, pois foram enterrados em vala comum, juntamente com outros judeus.

Para Ortiz (1994), o que torna um grupo coeso é a lembrança constantemente acionada de um território que seja um referencial para sua existência, de modo que não haja esquecimento, caso contrário este grupo pode se perder, sendo necessário vivificar e atualizar a memória para que o grupo não se dissolva. Assim, a vivificação da memória é necessária para que acontecimentos marcantes e que dizem respeito a toda humanidade não sejam esquecidos.

\section{CONSIDERAÇÕES FINAIS}

A Segunda Guerra Mundial deixou marcas indeléveis no mundo. A narrativa impressionante de uma garota de treze anos, forçada a deixar o conforto do seu lar para viver num esconderijo por causa da ocupação nazista na Holanda, causa sentimento de revolta, tristeza, indignação. Sem dúvida, um livro impactante, em que se torna difícil ficar indiferente a sua escrita. Em seu diário, Anne Frank relata os horrores ocorridos em um dos episódios mais terríveis da história da humanidade: o massacre de milhões de judeus (em sua maioria), que, sendo arrancados de suas casas, humilhados e tendo seus direitos mais básicos violados, perderam o maior direito de todos: o direito à vida, sem nenhuma justificativa plausível, a não ser o fato de serem judeus. 
Rev. Interd. em Cult. e Soc. (RICS), São Luís, v. 6, n. 1, p. 164- 172, jan./jun. 2020 ISSN eletrônico: $2447-6498$

De todos os moradores do Anexo, somente o pai de Anne Frank, Otto Frank, sobreviveu e foi ele que se encarregou de divulgar o diário de sua filha, que sonhava em ser escritora e que de certa forma conseguiu: "Quero continuar a viver, mesmo depois da minha morte", e Anne Frank continuou, mesmo depois de sua partida. Ao se ler o diário de Anne Frank, fica-se comovido e mesmo indignado ao ver a experiência traumática pela qual passou uma garota de apenas treze anos. Além desses sentimentos, fica também a vontade de conhecer o lugar onde tudo isso aconteceu, o que nos remete a praticar o turismo, viajar para conhecer, o que torna muito propícia a leitura. Nesse sentido, a Literatura, o Turismo e a Memória fazem com que a experiência de se ler o livro e conhecer o lugar onde ele foi escrito se torne única.

\section{REFERÊNCIAS}

BARRETTO, Margarita. Cultura e Turismo: discussões contemporâneas. Campinas: Papirus, 2007. (Coleção Turismo).

BLANCHOT, Maurice. O diário íntimo e a narrativa. In: . O livro por vir. São Paulo: Martins Fontes, 2005. p. 270-278.

FRANK, Anne. O diário de Anne Frank. Edição definitiva por Otto H. Frank e Mirjam Pressler: 21ª edição. Rio de Janeiro: BestBolso, 2013.

HALBWACHS, Maurice. A memória coletiva. Trad. Beatriz Sidou. São Paulo: Centauro, 2006.

HALL, Stuart. A identidade cultural na pós-modernidade. 11.ed. Rio de Janeiro: DPDA, 2011.

ORTIZ, Renato. Mundialização e cultura. [S.1]: Brasiliense, 1994.

PETROCCHI, Mario. Turismo: planejamento e gestão. 2. ed. São Paulo: Pearson Prentice Hall, 2009.

TUAN, Yi-Fu. Espaço e Lugar: a perspectiva da experiência. Trad. Lívia de Oliveira. Londrina, PR: EDUEL, 2013.

. Topofilia: um estudo da percepção, atitudes e valores do meio ambiente. Trad. Lívia de Oliveira. Londrina, PR: EDUEL, 2015. 